\title{
Raising awareness in dyers' community about the safe handling and disposal of dyes and related remedial solutions
}

\author{
Social Integration Outreach Program, Environment Protection \\ PROJECT COORDINATOR: Dr. SHAZIA NISAR \\ Department of Chemistry, University of Karachi \\ Email: shazian@uok.edu.pk
}

\begin{tabular}{ll}
\hline S. No. & TABLE OF CONTENTS \\
\hline 1 & Project Summary \\
2 & Goals of the Project \\
3 & Stages of the Project \\
4 & Progress against outputs and impacts \\
5 & Impact of the project on common men \\
6 & Number of beneficiaries from this project \\
7 & Overall Outcomes of the project \\
7.1 & $\quad$ Sustainability of the project \\
7.2 & $\quad$ Data Collection \\
8 & Results \\
9 & Observations \\
10 & Recommendations \\
\hline
\end{tabular}

\section{Project Summary:}

This project was aimed to build an understanding of the use of unauthentic dyes and chemicals and the impact they have both on the health of humans and environment. Students from the Department of Chemistry, University of Karachi were taught the impact of many dyes and food colors currently used in the market by local market dyers and food venders respectively.

There is a high level of both metal content and carcinogenic chemicals present in the dyes. These are absorbed into the body through ingestion, breathing and skin absorption. The dyes also have an impact on our groundwater supplies as many are disposed off down the drain. The chemicals combine to form cocktails more harmful to health. On hot days the chemicals evaporate and the fumes are also inhaled.

All these facts have made us to realize the need to raise awareness amongst the general public, which as consumers can induce venders to use higher quality products. This was done through questioning venders about the source of the dyes and food colorings used. The proposed project sought to raise the awareness about such dyes and issues by teaching students about dangers of unauthenticated dyes and food colors. The students were trained for safe handling and disposal of these hazardous compounds and surveyed the manufacturing plant having 0\% discharge at Archroma, a renowned multinational company manufacturing dyes and specialty chemicals. The students were then asked to go to their local vendors and survey the current use of dyes and food colors. The survey forms were collected by the Department of Chemistry and data collated to indicate the current practices of both dye and knowledge of impacts in the local vendor communities in the city.

\section{Goals of the Project:}

- Raise awareness in at least 150 students about the use of unauthenticated dyes and food colors which are not certified.

Educate and train students about the safe handling and safe disposal of dyes and related chemicals used in their communities.

- Use of Biomass for the removal of dyes from aqueous solution

- Facilitate and encourage students to go to their local venders and make them aware and provide them remedial solutions in form of audios, videos and booklet.

- Collect data on the use of dyes and products in their communities through a survey conducted by students.

- Develop a report which can be used as an awareness exercise to write in newspaper articles and booklet. 


\section{Stages of the Project:}

- Introductory Awareness Seminar

- Workshop

- Hands on Training

- Visit to Effluent treatment Plant at Archroma (PVT) Ltd, Jamshoro

- Survey to the local markets

- Collection of the Data

- Compilation of the data

\section{Progress against outputs and impacts}

This project was proposed with the aim of encouraging the use of economically and ecologically sustainable dyes. The other benefits, successfully achieved are as follows;

- The students were trained through awareness seminar, workshop, training session and visits to effluent treatment plant at Archroma, Jamshoro.

- The students learnt the safe handling and disposal of dyes through practicing the procedures in workshop and training sessions.

- The trained students have actively participated and contributed towards raising awareness among local dyers' community by visiting venders in local markets, teaching them safe methods of handling and disposing of dyes and replacement of substandard dyes with the standardized ones.

- The venders have realized the threats (health and environmental) associated with these dyes and many have promised to replace the substandard dyes with the standardized ones.

- They have promised to ensure proper handling of these dyes.

- They have also taken the responsibility of preventing the contamination of streams by practicing safe methods of disposal of dye-bath thereby reducing their toxic effects.

- The dyers were provided with standardized dyes' (product of Archroma PVT., LTD.) samples and their preference over the local substandard dyes was explained.

- The venders were also taught the use of easily available biomasses such as grape stalks, hazelnut and almond shells, Capsicum annuum seeds, citrus wastes, rice husk, sugarcane bagasse, corncobs and cotton stick and barely husk for the removal of dyes from aqueous solution

- The importance of conservation of water in terms of sustainability was explained and hence the recycling of water was encouraged and the venders were also made realize the reduction in financial burden in terms of water supply.

\section{Impact of the project on common men}

\begin{tabular}{|l|l|l|}
\hline S. No & Impacts & Explanation \\
\hline 1 & Health & $\begin{array}{l}\text { Many have become aware of the health hazards (such as, Asthma, skin allergies, } \\
\text { burning sensation in eyes) due to use of substandard dyes and their mishandling. }\end{array}$ \\
\hline 2 & Environment & $\begin{array}{l}\text { Have realized the environmental threats related to the disposal of these dyes into main } \\
\text { streams and have promised to practice safe methods of disposal in order to reduce the } \\
\text { environmental contamination }\end{array}$ \\
\hline 3 & $\begin{array}{l}\text { Conservation of } \\
\text { water }\end{array}$ & $\begin{array}{l}\text { Learnt, the ways of recycling of water through the use of wasted biomass, such as } \\
\text { sugarcane, rice husk, etc., }\end{array}$ \\
\hline 4 & $\begin{array}{l}\text { Waste } \\
\text { management }\end{array}$ & have known the safe and economic ways of waste management \\
\hline
\end{tabular}

\section{Number of beneficiaries from this project}

1. Students have gained knowledge about

a) Health hazards and environmental threats related to the use of dyes

b) Safe handling and disposal

2. Local venders have learned

a) Health hazards and environmental threats related to the use of dyes

b) Safe handling and disposal 
Nisar, 2018

c) The ways to improve their health

d) Use of wasted biomass in water treatment

The venders will become financially strong as the quality of dyes will affect the durability of color on dyestuff thereby increasing the trust of customer in venders.

3. Companies manufacturing standardized dyes and chemicals. Their sale will increase.

4. The whole community's health issues will be minimized and waste management will be focused on more seriously.

\section{Overall Outcomes of the project}

\subsection{Sustainability of the project}

A lot of data has been collated through the project which researchers, lecturers and students can use for future reference about teaching on environment-related issues. The Department will also conduct an annual awareness drive with students going out in the community to collect data.

\subsection{Data Collection}

Data about the practices employed by dyers in the markets of Karachi was undertaken. A two tiered questionnaire was filled in by enumerators. Part A of the questionnaire collected data about the physical observations of the site. Part B of the questionnaire was filled in by taking an interview of the dye shop owner. The results from the questionnaire can then be used to infer the practices related to quality assurance and health and safety. This can be looked upon as a preliminary study.

\section{Results}

40 dye-owners were surveyed in various locations of Karachi. The localities included: Paposh Nagar, Karimabad, Defence Housing Authority Phase 1 and Tariq Road. The dyers have been working for period of 4-37 years in these localities. In terms of the type of dyeing facilities, for Part A, observations were made in the dye workshop.

\section{Observations:}

Table 1: Observation in the workshop

\begin{tabular}{|l|l|l|l|l|l|l|}
\hline Exhaust Fan & $\begin{array}{l}\text { Window in } \\
\text { Facility }\end{array}$ & $\begin{array}{l}\text { Gutter for } \\
\text { disposal }\end{array}$ & $\begin{array}{l}\text { Overall for } \\
\text { workers }\end{array}$ & Face Mask & $\begin{array}{l}\text { Hand Wash } \\
\text { Area }\end{array}$ & Drying Area \\
\hline $14 \%$ & $93 \%$ & $93 \%$ & 0 & $7 \%$ & $28.6 \%$ & $28.6 \%$ \\
\hline
\end{tabular}

The observations show that only basic facilities are present in most of the dye workshops. These are the presence of a gutter and a window in the facility. There is little evidence of basic requirements for health and safety in the workplace with a lack of exhaust fans, hand wash area etc.

Part two of the questionnaire identified a perspective of the dyers on quality and health and safety.

\section{Quality Assurance of Dyes}

Dyers were asked 6 questions in relation to developing quality.

\section{Table 2: Dyers on Quality Review}

\begin{tabular}{|c|c|}
\hline Question & Responses from Dyers \\
\hline 1. How do you check for the quality of color? & $100 \%$ responded by observation. \\
\hline 2. What are the chemicals you add to the product? & $78 \%$ responded they use salts and phenyls. \\
\hline 3. Which are the colors that bleed? & 93\% responded green and turquoise bleed. \\
\hline 4. What new techniques have you started applying? & $7 \%$ reported on the use of fixatives \\
\hline 5. Have you been given any training in dyeing & $7 \%$ said yes \\
\hline 6. Would you like to learn about new practices? & $78 \%$ said yes \\
\hline
\end{tabular}

\section{Health and Safety Practices}

In relation to health and safety dyers were asked 4 questions. Only a few dyers responded to the questions. 
Table 3: Dyers Responses related to Health and Safety

\begin{tabular}{|l|l|}
\hline $\begin{array}{l}\text { Question } \\
\text { dyes? }\end{array}$ & \multicolumn{2}{|c|}{$\begin{array}{l}2 \text { responses included: breathing issues, 1 response identified skin } \\
\text { rashes }\end{array}$} \\
\hline 2. How do you deal with the issue? & $\begin{array}{l}1 \text { response identified drinking lots of water, One response } \\
\text { identified taking medication }\end{array}$ \\
\hline $\begin{array}{l}\text { 3. When working with dyes, have you ever felt } \\
\text { your eyes burning, skin itching or throat } \\
\text { burning? }\end{array}$ & $\begin{array}{l}1 \text { response identified the eyes itching. } \\
1 \text { response identified itchy throat. }\end{array}$ \\
\hline 4. How did you resolve the issue? & 1 response identified washing area with water \\
\hline
\end{tabular}

\section{Source of Dyes}

Dyers identified 4 sources where they buy dyes: Lalukhait, Burns Road, Jodia Bazaar, Liaquatabad.

\section{Disposal Methods of Dyes}

\begin{tabular}{|c|c|}
\hline Question & Response \\
\hline 1. How do you dispose of the dye waste? & $100 \%$ responded disposed directly down the drain \\
\hline $\begin{array}{l}\text { 2. Do you know of any other method of } \\
\text { disposing dyes? }\end{array}$ & $100 \%$ responded in the negative \\
\hline $\begin{array}{l}\text { 3. Are you aware of using disposal and } \\
\text { treatment techniques of rice husks, sugar } \\
\text { cane husks and almond peels? }\end{array}$ & $100 \%$ responded in the negative \\
\hline
\end{tabular}

\section{How do dyers feel about the family working in the business?}

$71 \%$ of dyers responded they would not like their children to work in the business. Reasons given were that there is no profit margin, children are educated and so they can get better jobs, and industry is taking over dyeing.

\section{Observations}

Based on the results, it can be identified that:

- There is little awareness on health and safety in the workplace

- There is little awareness on the impact on health by the use of dyes

- No mention of the impact on the environment from dyes

- No quality assurance process is visible in dyer practices - trial and error method is employed

- Little evidence is given on dyers being trained

\section{Recommendations}

- There is a need to understand what can make dyers more aware of the impact of dyes and the environment

- A greater understanding of social issues can be used to bring out local solutions in research initiatives of Chemistry Department

- Research, training and awareness on disposal techniques

- An annual drive by students in the local communities can help the continuity of the approach to raise awareness

- Development of policy and guidelines is a dire need. 